\title{
Whose body is this?
}

I first wondered whether I had amyotrophic lateral sclerosis in the summer of 2013. I was pouring coffee and dropped the coffee pot on the table. My right shoulder just gave out. Why did I have shoulder weakness? I hadn't injured it. Although it occurred to me that painless weakness is a symptom of amyotrophic lateral sclerosis, I convinced myself that it was just trainee hypochondriasis — as a neurology resident, I'd seen patients at every stage of this disease - and put it out of my mind. I expected that my shoulder would simply get strong again. Unfortunately, it did not improve, and continued to weaken.

Over the next few months, I had increasing difficulty reaching for objects with my right arm. I started having frequent fasciculations and cramps, first in the right shoulder muscles and then the left, and widespread atrophy of my right shoulder muscles, spreading to the left shoulder soon after. The fasciculations became constant and were keeping me up at night. I could no longer attribute this to trainee hypochondriasis. Something was seriously wrong. Despite months of progressive symptoms, I had told no one. Denial is powerful.

I eventually worked up the courage to go the electromyography (EMG) laboratory to face my fears. As a neurology resident, I had seen many patients there, but today I was the patient. I could sense my mentor's concern when he found that I was hyperreflexic despite the atrophy. I had both upper and lower motor-neuron findings - a hallmark of amyotrophic lateral sclerosis (ALS). Once the EMG exam started, it didn't take long to hear the characteristic sound of denervation that some describe as "rain on a tin roof" or the "ticking of a clock." To me (and my mentor) it sounded like ALS. I wondered if I had seen my last patient. How would I break the news to my family?

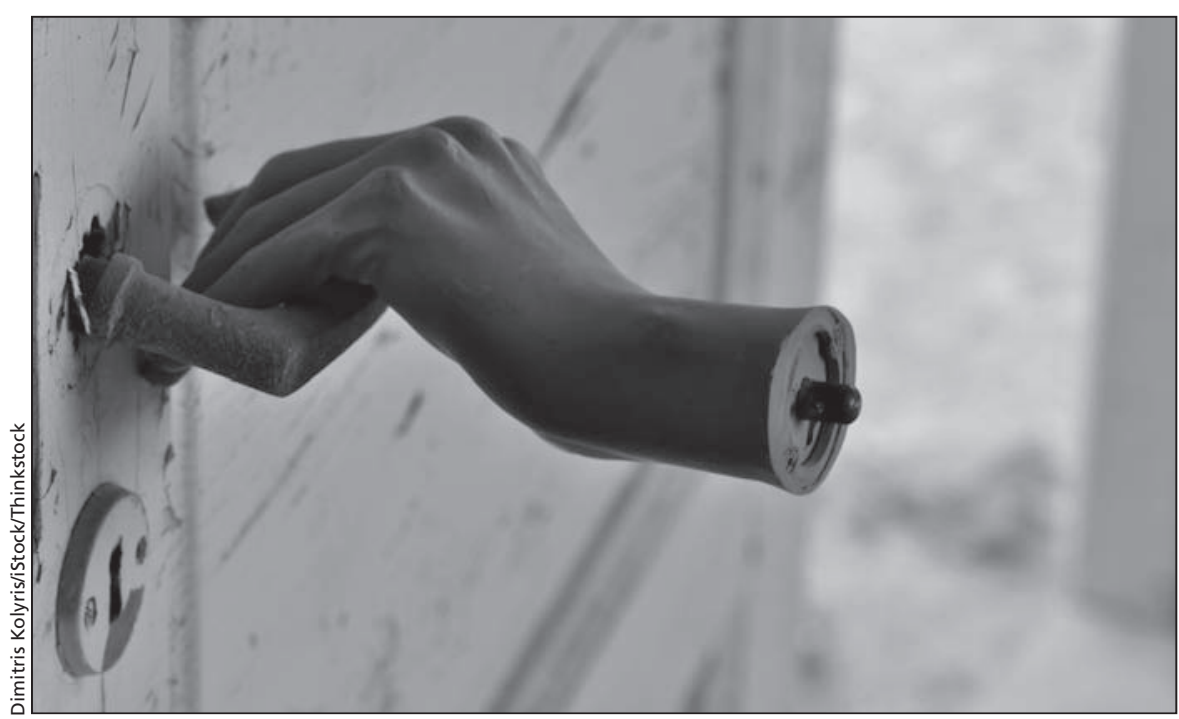

How much time did I have left?

I would lose control of one bodily function after another until I was quadriplegic, unable to swallow, unable to speak and unable to breathe, and not necessarily in that order. I wanted to break the news to my parents in person.

On my way out of the city, I stopped to visit a friend and fellow neurology resident. I explained that I probably had ALS. I said, "You're one of the only ones that truly understands what I'm up against." We hugged and cried. My friend insisted on driving me the rest of the way.

A lot became clear to me on that car ride home. I realized that my greatest achievements were not being valedictorian of my high school graduating class, completing a $\mathrm{PhD}$, publishing research articles, graduating from medical school or being accepted into my residency program. Instead, I was most thankful for my life experiences and adventures. I was grateful that I had already been living my life as if something like this would happen to me. I have always loved the James Dean quote: "Dream as if you'll live forever; live as if you'll die tomorrow." I had crossed a lot of items off my bucket list, but the grief came in waves when I thought of all the things I still wanted to do.

I also thought about how my quality of life would be infinitely greater if I had control over the manner and timing of my death. I was more afraid of suffering than I was of death. Without control, the existential suffering felt so profound as to eliminate any quality of life. How could I enjoy the present knowing what was coming?

I thought about Sue Rodriguez, a patient with ALS in British Columbia who bravely argued all the way to the Supreme Court of Canada for the right to die by physician-assisted suicide. She lost her case in a landmark five-to-four decision in 1993. Her words "If I cannot give consent to my own death, whose body is this? Who owns my life?" have been echoing through the Canadian consciousness ever since. I realized that whatever happened to me, I wanted to help legalize doctor-assisted suicide in Canada. I felt that this was the right choice, not because of any specific ethical or legal arguments, but because of my own feelings while facing death.

I felt a stab of anger as well. Why me? Why now? I had taken many risks 
in my life. I had ridden my motorcycle through 45 countries. Why couldn't I have died in a motorcycle crash or been shot by bandits? I'd had many near misses. Why survive all of them only to die a slow agonizing death now?

When we pulled into my parents' driveway I became distraught. I knew the news I was bringing would devastate my parents, and the thought of them having to watch me waste away and become my caregivers filled me with sadness. I was supposed to be their caregiver one day, not the other way around. But I pulled myself together and said to my friend, "We're going to go in and put on a show," and we did. We had one last night of normal before I broke the news to them the next day.

Sitting outside with my parents, watching the sun set, I told them I had been getting weaker for the last few months and that it might be ALS. My mom was emotional. My dad, the optimist, said, "There's still a chance it's something else, right? This is not for sure yet."

I've ordered countless MRIs over the years. Now it was my turn in the tube. Lying on the cold slab, my body wracked by fasciculations, I felt like a corpse.

The hours after the MRI were the darkest of my life. The snow fell wet and heavy all afternoon. I was lost in dark thoughts. Then my mentor called me with the MRI results. He explained that there was an extradural cerebrospinal fluid (CSF) collection throughout my cervical and thoracic spine that was compressing my ventral roots. There was reason to be optimistic. He had seen a couple of cases like this before. He sent me a link to a case report that was similar. My life changed. I was flooded with the sweetness of hope.

The CSF collection was due to a residual traumatic dural tear from a snowboarding crash eight years earlier. I never suspected a rare progressive bibrachial amyotrophy mimicking ALS as a result.
I underwent a posterior laminectomy and surgical repair of the dural tear. Since the surgery, my strength has been gradually improving. Although I may never fully recover, I am grateful that I am getting stronger each day. I have been given another chance at life.

The emotional impact of facing my own death, and worse, becoming trapped in my own body, has changed me. I have gained a tremendous empathy for terminally ill patients who want help ending their lives. There is no way that my experience as a patient could not affect me as a doctor. I have witnessed the awesome power of a correct diagnosis. I have not seen my last patient after all.

\section{Tyson B. Brust MD PhD}

PGY4 neurology resident

Department of Neurology

University of Calgary

Calgary, Alta.

CMAJ 2014. DOI:10.1503/cmaj.140287

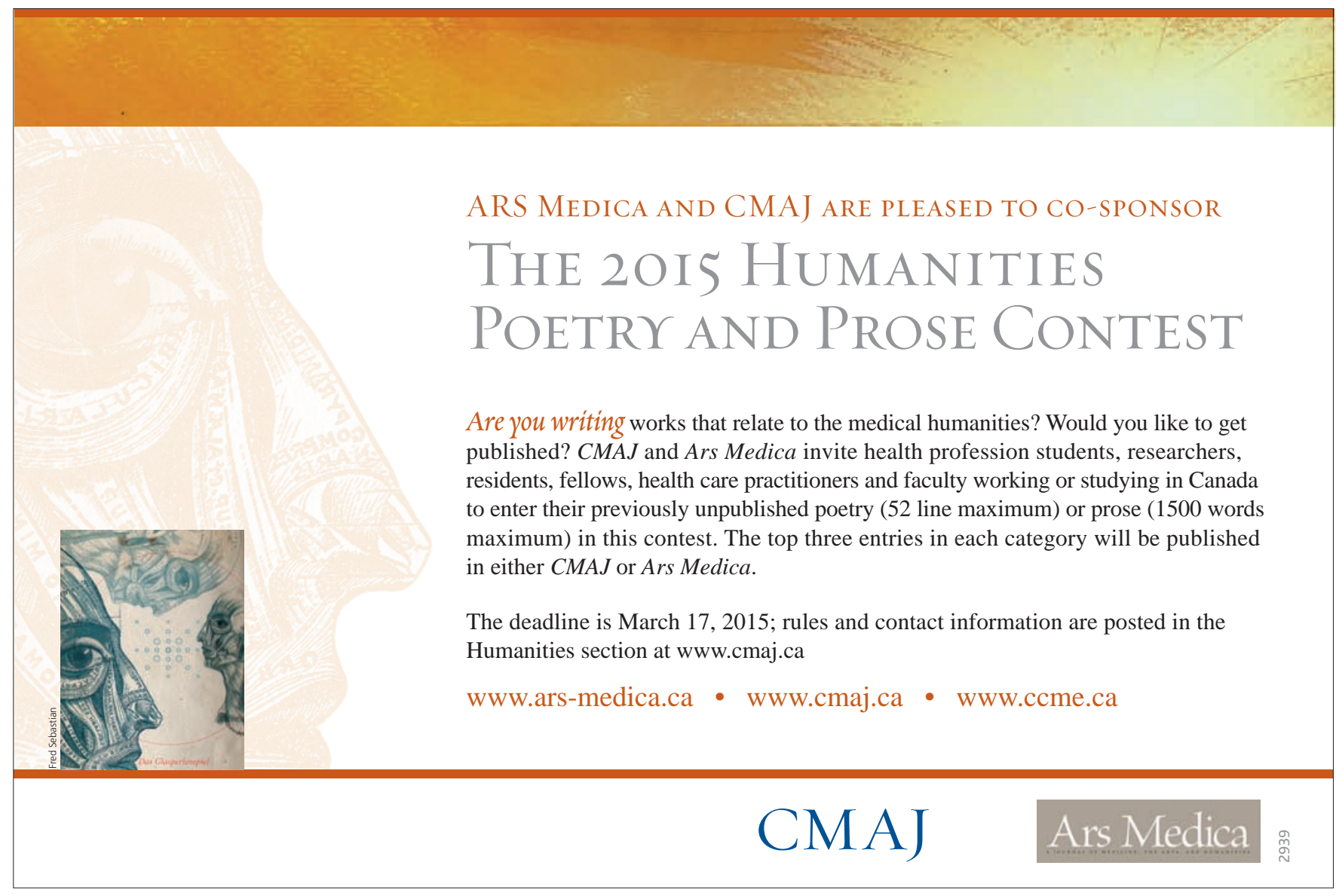

